\title{
Surface Structure Controls Self-Metalation: \\ In-Situ IR studies of Anchored Porphyrins on Atomically-Defined Cobalt Oxide Surfaces
}

\author{
Tobias Wähler ${ }^{1}$, Ralf Schuster ${ }^{1}$, Jörg Libuda ${ }^{1, *}$ \\ ${ }^{1}$ Interface Research and Catalysis, Erlangen Center for Interface Research and Catalysis (ECRC), \\ Friedrich-Alexander-Universität Erlangen-Nürnberg, Egerlandstraße 3, 91058 Erlangen, Germany \\ *corresponding author: joerg.libuda@fau.de, +499131 85-67661
}

\section{Supporting Information}

\section{Contents}

Time-resolved spectra of the measurements at $300 \mathrm{~K}$ and $450 \mathrm{~K}$ shown in the manuscript. Comparison of adsorption geometries of surface anchored carboxylates formed on $\mathrm{Co}_{3} \mathrm{O}_{4}(111)$ and $\mathrm{CoO}(111)$. Heat maps of temperature-programmed measurements between $150 \mathrm{~K}$ and $650 \mathrm{~K}$ on $\mathrm{Co}_{3} \mathrm{O}_{4}(111)$ and $\mathrm{CoO}(111)$. 
Time-resolved IR spectra
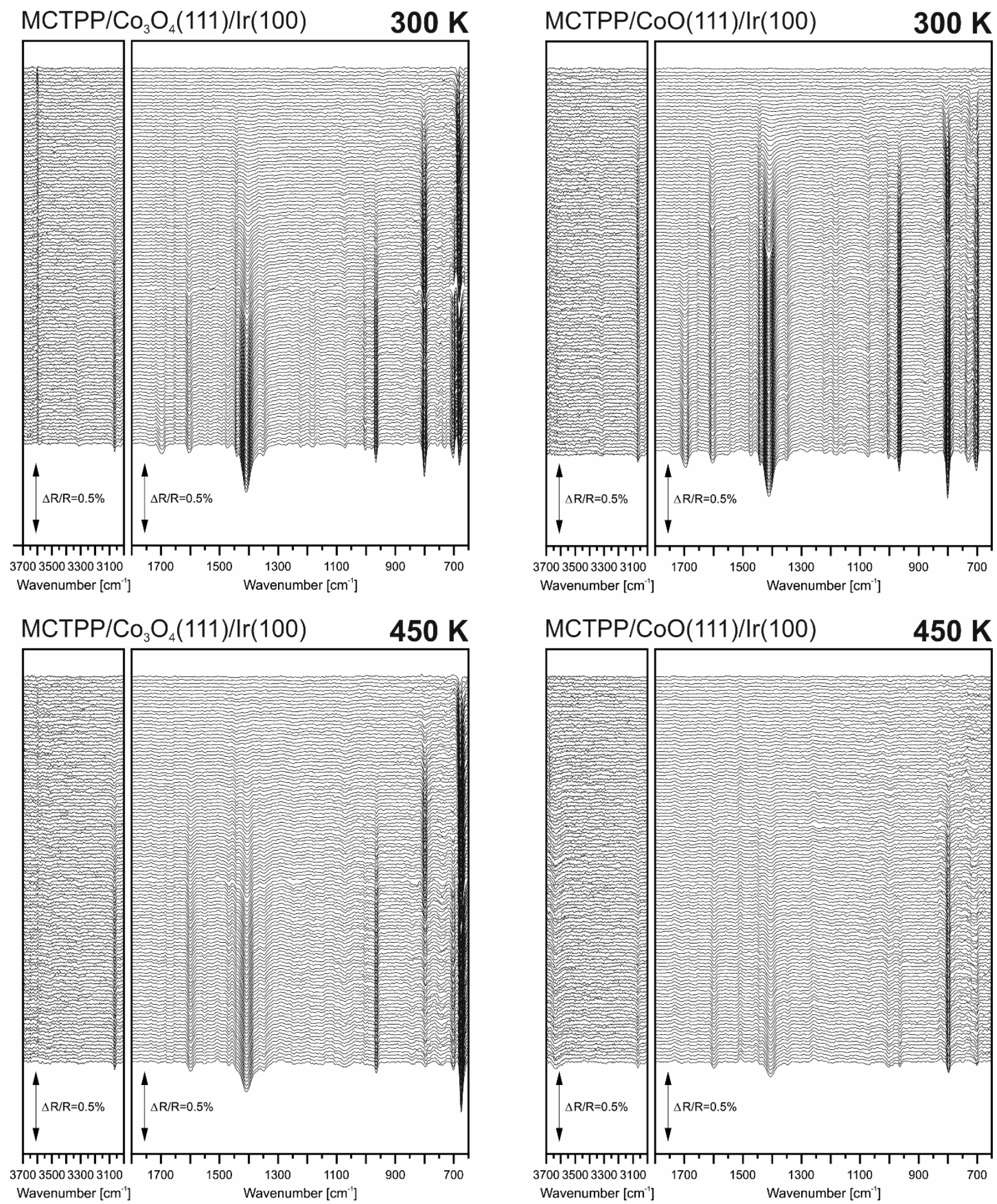

Figure S1. Time-resolved IRAS spectra of MCTPP adsorbed on $\mathrm{Co}_{3} \mathrm{O}_{4}(111)$ (left panel) and $\mathrm{CoO}(111)$ (right panel) at $300 \mathrm{~K}$ and $450 \mathrm{~K}$ (note that on $\mathrm{CoO}(111)$ at $450 \mathrm{~K}$ no fully saturated monolayer coverage was achieved). 


\section{$v_{s}(\mathrm{O}-\mathrm{C}-\mathrm{O})$ of} surface carboxylate

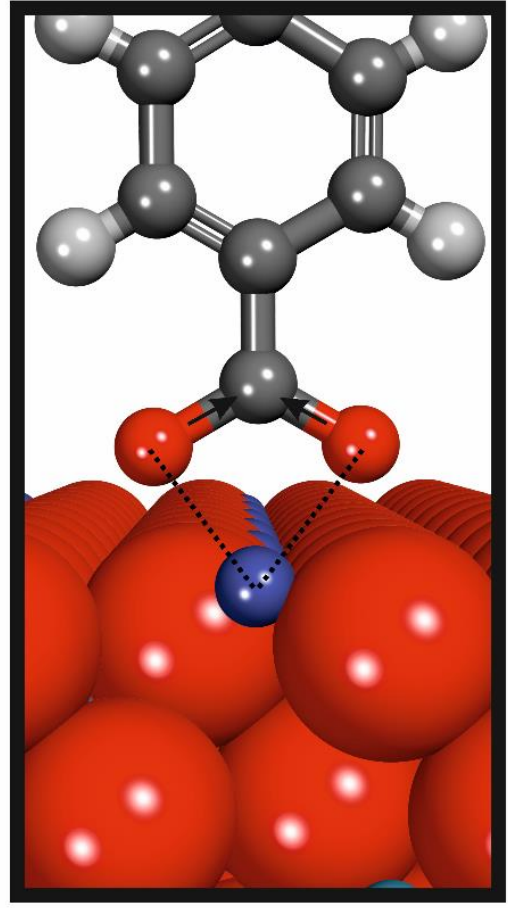

chelating bidentate e.g. on $\mathrm{Co}_{3} \mathrm{O}_{4}(111)$

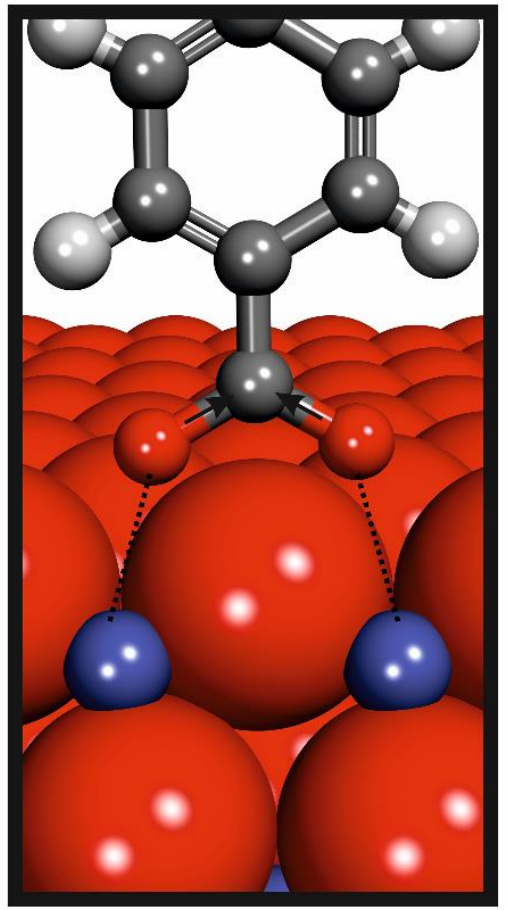

bridging e.g. on $\mathrm{CoO}(111)$

Figure S2. Adsorption geometries of surface anchored bridging and chelating bidentate carboxylates on $\mathrm{Co}_{3} \mathrm{O}_{4}(111)$ and $\mathrm{CoO}(111)$, respectively. 

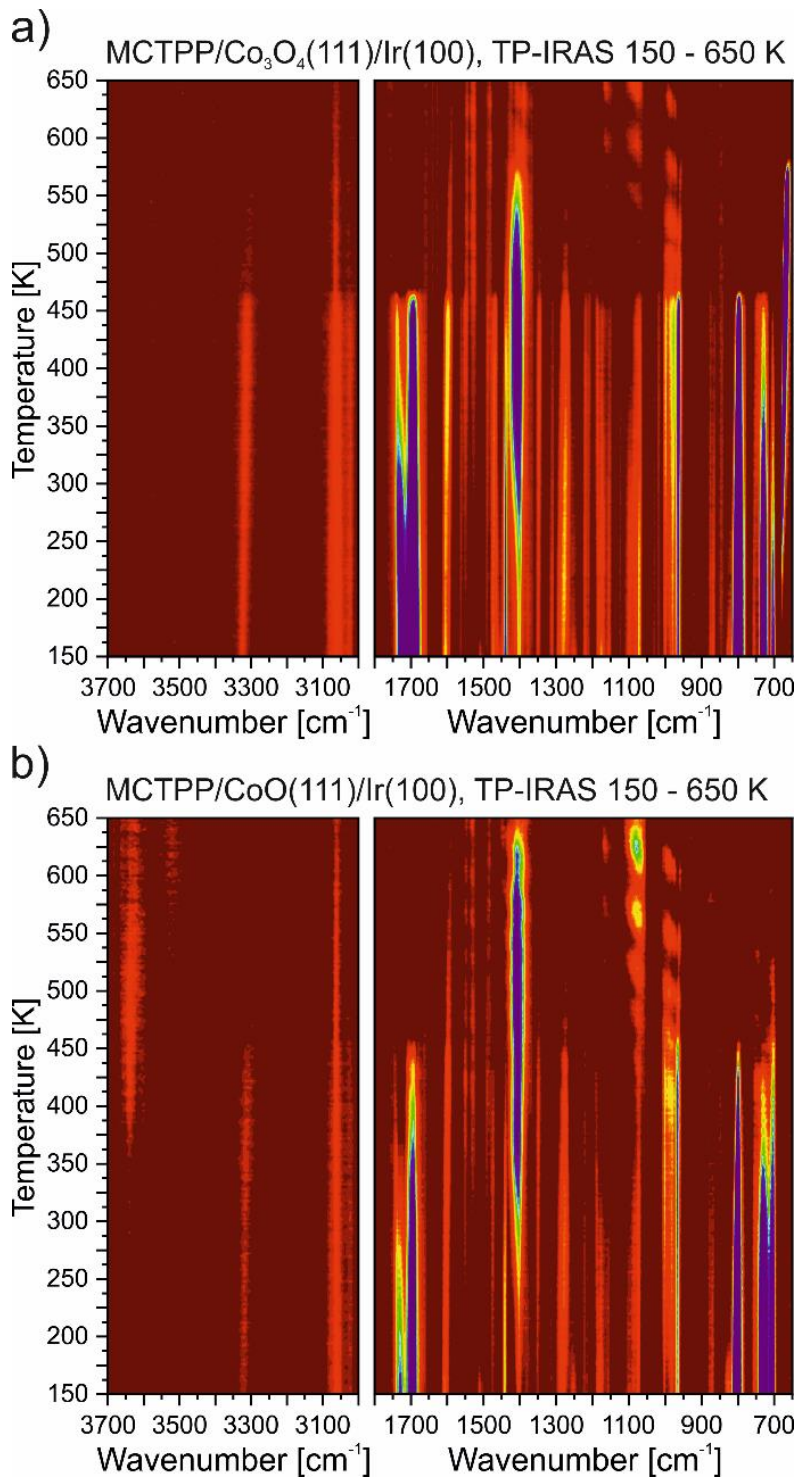

Figure S3. Heat maps of temperature-programmed measurements from $150 \mathrm{~K}$ to $650 \mathrm{~K}$ on a) $\mathrm{Co}_{3} \mathrm{O}_{4}(111)$ and b) $\mathrm{CoO}(111)$, respectively. 